\title{
Breast self-examination among nurses in Poland and their reparation in this regard
}

\author{
Magdalena Woynarowska-Sołdan ${ }^{1, A, C-E \oplus}{ }^{\oplus}$, Mariusz Panczyk ${ }^{1, A, C-F} \oplus$, Lucyna Iwanow ${ }^{1, B} \oplus$, \\ Grażyna Bączek ${ }^{1, B-C \oplus}$, Robert Gałązkowski ${ }^{1, A, E \oplus}$, Joanna Gotlib ${ }^{1, A, E-F} \oplus$ \\ ${ }^{1}$ Medical University, Warsaw, Poland \\ A - Research concept and design, B - Collection and/or assembly of data, C - Data analysis and interpretation, \\ $D$ - Writing the article, E - Critical revision of the article, F - Final approval of article
}

\begin{abstract}
Woynarowska-Sołdan M, Panczyk M, Iwanow L, Bączek G, Gałązkowski R, Gotlib J. Breast self-examination among nurses in Poland and their reparation in this regard. Ann Agric Environ Med. 2019; 26(3): 450-455. doi: 10.26444/aaem/102762
\end{abstract}

\begin{abstract}
Introduction and objective. Working at night and in shifts, as well as an unhealthy lifestyle, may increase the risk of breast cancer in nurses who therefore should frequently perform breast self-examination (BSE). The aim of the study was to investigate the performance of BSE among Polish nurses, its accuracy, sources of knowledge and skills, self-assessment of own competences and preparation to educate women about BSE.

Materials and method. A descriptive, cross-sectional study was conducted in a group of female nurses ( $N=1,242)$. An anonymous, self-administrated questionnaire was used for data collection. To properly assess the BSE a four-item scale was made of the type single best answer multiple choice question. Each item referred to one agreed principle of performing BSE. Results. Regularly BSE was performed by $56.1 \%$ nurses, $67.3 \%$ pre-menopause nurses $2-3$ days after cessation of menstruation and $30.4 \%$ post-menopause women on a chosen day of the month. About $98 \%$ examined visually and by palpation; $58.9 \%$ did so in two positions. In the accuracy scale of BSE, the average number of points was 2.8 out of 4 . All (4 points) or almost all (3 points) recommendations of accurate BSE were met by $61.4 \%$ of the nurses. Self-assessment of knowledge and BSE practical skills were considered as good or very good by $93.5 \%$ and $88.8 \%$ nurses, respectively. The self-evaluation of nurses' knowledge and BSE skills was significantly correlated with the result on the accuracy scale or this BSE.

Conclusions. Many deficiencies concerning frequency, times and BSE techniques were revealed among Polish nurses. There is a discrepancy between the high self-assessment of competences and the accurate practice of BSE. Nurses' preparation in Poland in BSE is insufficient and requires improvement.
\end{abstract}

\section{Key words}

cancer, prevention, breast self-examination, nurses

\section{INTRODUCTION}

In Poland, similar to other European countries, breast cancer is a major cause of female mortality. In 2014, breast cancer was responsible for $21.7 \%$ of all cancer among women and $13.9 \%$ of cancer deaths [1]. In the last three decades the incidence rate for this cancer has more than doubled, and in the group of pre-menopausal women has increased about 1.7 times [2]. In comparison with the other countries of Europe, in Poland the incidence rate and mortality rate due to breast cancer is not high (respectively, 48.9 and 14.7 per 100,000 inhabitants) [3], but the 5-year net survival for patients diagnosed with breast cancer in Poland was the lowest in Europe (74\%) [4, 5]. This is the consequence of late diagnosis of the disease.

For the detection of breast cancer in its earliest stages, regular screening of all women is recommended. There are three methods of screening: breast self-examination (BSE), clinical breast examination and mammography [6]. Mammography in Poland is free of charge for women aged 50-69, performed once every two years [7]. Participation rate in this screening test is among the lowest in the European Union (EU), and the percentage of women in Poland screened in 2013 (of the total number of women invited personally that

Address for correspondence: Joanna Gotlib, Medical University of Warsaw, Żwirk i Wigury 61, 02-791, Warszawa, Poland

e-mail: joanna.gotlib@wum.edu.pl

Received: 14.12.2018; accepted: 11.01.2019; first published: 04.03.2019 year) was $44 \%$. The participation rate for this age group in the EU was 60.2\%, with the highest in Denmark 83.5\% [8].

Breast self-examination is an easy, economic, non-invasive method for all women aged over 20. The purpose of BSE is for a woman to learn the topography of her breast, know how her breast normally feels and to be able to identify changes in the breast should they occur in the future. BSE consists of two basic steps: visual examination in the standing position and tactile examination carried out lying down or standing up. This examination should be performed frequently by menstruating women, preferably 2-3 days after each menstruation, and by post-menopausal women once a month on a chosen day, e.g. on their birthday $[9,10]$.

BSE efficiency in the reduction of the number of deaths from cancer is currently a source of controversy $[6,9,11,12]$. This method is considered adequate when performed at least once per month [13], and should be used in combination with mammography and clinical examination [9]. When performed, BSE increases breast cancer awareness which means knowledge of the personal/family history, risk factors for breast cancer, and anatomical structure and appearance of own breast [14]. When performing BSE, women have an opportunity to observe and feel their breast, to be familiar with the texture of their normal breast tissue, and how it changes at different times of the month and with age, report changes without delay, and attend for breast screening when aged 50 and over [11]. It was found that in the United Kingdom breast cancer awareness increased the uptake 
of BSE behaviours and the likelihood of the breast cancer screening attendance [15]. The American Cancer Society (2016) [16] no longer recommends that all women perform monthly BSE, but concluded that:

... all women should become familiar with both the appearance and feel of their breasts and report any changes promptly to their physician. Women who detect their own breast cancer usually find it outside of a structured BSE while bathing or getting dressed. If symptoms develop, women should contact a doctor immediately, even after a recent normal mammogram.

In Poland, all women aged 20 and older are recommended to perform BSE frequently as an important element in the early detection of breast cancer [10].

Undertaking research of the practice of BSE by nurses and their preparation in this regard was justified by several reasons. For many years, the majority of nurses perform night shift work which may be related to an increased risk of development of breast cancer. An association between rotating night work and breast cancer and a positive trend between cancer risk and duration of night work and number of consecutive night shifts were found in American nurses [17, $18]$ and in Norwegian nurses $[19,20]$. Exposure to light at night has been hypothesized to influence this cancer risk among persons with night work, as a result of a decrease in of the secretion hormone melatonin, and a subsequent increase in estrogens [21-23]. The International Agency for Research on Cancer decided that shift work involving circadian disruption is probably carcinogenic for human [24]. In Denmark, breast cancer has been recognized as an occupational disease [25]. Further meta-analyses of epidemiological studies concluded that there is limited evidence for a causal association between night-shift work and breast cancer risk [26-29]. Despite these concerns nurses should be aware of the risk related to this type of work, frequently perform BSE, systematically attend mammography if over 50 years of age, and limit other factors which influence the risk of breast cancer. Such factors also include the deficits in the health behaviour of nurses, including low physical activity, poor dietary quality, smoking, and excessive consumption of alcohol [30-33].

Nurses should play an important role in educating women about cancer. Therefore, the experience and knowledge of nurses with BSE are essential for reducing the mortality of breast cancer. Furthermore, nurses' beliefs and confidence in the importance of BSE would make a difference while teaching the BSE method and encouraging women to perform it.

The literature offers relatively few papers about performing BSE by nurses. The available papers concern nurses and female health care workers in Asia, i.e. Turkey [34], Iran [35, 36], Pakistan [37], India [38], and the United Arab Emirates [39]. The number of examined persons in these countries was small (from 119 to 410). In these countries research was conducted also among nursing students on performing BSE and knowledge about factors which affect breast cancer [40, $41,42,43]$. In these countries, breast cancer is becoming an increasing problem, but mammography services are almost non-existent. In the literature, no publication was found on performing BSE by nurses and their preparation to prevention of breast cancer in Europe. Only one paper on BSE by nursing students in Cyprus [44] was found.

\section{OBJECTIVE}

The aim of this study is to present the results of the research concerning the following: 1) performing BSE by nurses, proper examination and sources of knowledge and skills in this respect; 2) self-evaluation of the knowledge, skills of performing BSE and the relationship between self-evaluation and accuracy of BSE, as well as self-evaluation of nurses' preparation to educate women in this respect.

\section{MATERIALS AND METHOD}

A descriptive, cross-sectional study was conducted in a group of female nurses participating in a national specialist examination. Inclusion criteria: female, right to practice the profession, professional activity in nursing, at least two years of work experience, completed specialist training.

Calculation of the sample size was performed by taking into account the following criteria: size of the population 240,000 (number of registered nurses in Poland), confidence level $-95 \%$, response distribution -0.50 , and margin of error $-3 \%$. The optimal sample size was 1,250 (15\% surplus was included).

There were 1,242 properly filled out questionnaires (interest in survey return was $49.7 \%$ of all participants in the examination). Analysis included the information from the questionnaire where respondents gave complete answers according to the instruction. The surveyed nurses were attempting to obtain different nursing specialities. Average age $-43.2 \pm 7.05$ (median: 44.0, $\min 25.0$ and $\max 61.0$ ), which was representative of the participating population $(t=0.419$, $\mathrm{df}=1241, \mathrm{P}=0.675$ ). Analyses divided the respondents into two age categories - younger nurses up to 44 and older 45 or more years ( 663 vs. $579, \chi^{2}=5.68, \mathrm{P}=0.017$ ). The majority $(68 \%)$ of nurses had higher education (master or licentiate degree), and the percentage of higher education respondents was significantly higher in the group of younger nurses than in the older ones $\left(73.9 \%\right.$ vs. $\left.60.3 \%, \chi^{2}=26.20 ; \mathrm{P}<0.001\right)$. Shift work was performed by $81.1 \%$ of younger nurses and $71.1 \%$ of older ones $\left(\chi^{2}=17.71 ; \mathrm{P}<0.001\right)$. Socio-demographic characteristics of the study sample are shown in Table 1.

The study was approved by the Bioethics Committee of the Medical University of Warsaw (AKBE\169\16).

Data collection. The data were gathered in the entire group on the date and at the place of the specialist examination in Warsaw by the Centre for Postgraduate Education for Nurses and Midwives from September - November 2016. The survey participants worked at various health care centres in different regions of Poland. Participation in the survey was voluntary. An anonymous, self-administrated, pre-tested, structured, close ended questionnaire was used for data collection.

Questionnaire. The questionnaire contained the following areas: 1) socio-demographic characteristics of the study subjects; 2) their practice of breast self-examination (BSE) (age at first examination; regularity of examination, time of its performance in the menstrual cycle (in pre-menopausal nurses or in the month in post-menopausal women, examination position and technique of performing the examination); 3) self-assessment of their knowledge and practical skills concerning BSE, their sources, self-assessment 
Table 1. Socio-demographic characteristics of the study sample

\begin{tabular}{|c|c|c|c|}
\hline & $\begin{array}{l}<45 \text { years } \\
(\mathrm{N}=663)\end{array}$ & $\begin{array}{l}\geq 45 \text { years } \\
(\mathrm{N}=579)\end{array}$ & $\begin{array}{c}\text { Total } \\
(1,242)\end{array}$ \\
\hline \multicolumn{4}{|l|}{ Place of residence } \\
\hline Countryside & $189(28.5)$ & $170(29.3)$ & $359(28.9)$ \\
\hline Village (population up to 50 thousand) & $149(22.4)$ & $120(20.8)$ & $269(21.7)$ \\
\hline Small town (51-200 thousand inhabitants) & $157(23.7)$ & $112(19.4)$ & $269(21.7)$ \\
\hline Large town (201-500 thousand inhabitants) & $87(13.1)$ & $87(15.0)$ & $174(14.0)$ \\
\hline City $>500$ thousand inhabitants & $81(12.3)$ & $90(15.5)$ & $171(13.7)$ \\
\hline \multicolumn{4}{|l|}{ Education } \\
\hline Secondary medical & $169(25.5)$ & $223(38.5)$ & $392(31.6)$ \\
\hline Bachelor's degree & $241(36.4)$ & $197(34.0)$ & $438(35.3)$ \\
\hline Master's degree & $249(37.5)$ & $152(26.3)$ & $401(32.3)$ \\
\hline Ph.D. & $4(0.6)$ & $7(1.2)$ & $11(0.8)$ \\
\hline \multicolumn{4}{|l|}{ Specialisation } \\
\hline Surgical nursing & $135(20.3)$ & $113(19.5)$ & $248(20.0)$ \\
\hline Anaesthesiological nursing & $125(18.8)$ & $98(17.0)$ & $223(18.0)$ \\
\hline Conservative nursing & $92(13.9)$ & $76(13.1)$ & $168(13.5)$ \\
\hline Geriatric nursing & $67(10.1)$ & $66(11.5)$ & $133(10.7)$ \\
\hline Oncology nursing & $58(8.8)$ & $50(8.7)$ & $108(8.7)$ \\
\hline Cardiological nursing & $38(5.8)$ & $32(5.5)$ & $70(5.6)$ \\
\hline Long-term nursing & $37(5.7)$ & $25(4.3)$ & $62(5.0)$ \\
\hline Operating room nursing & $32(4.8)$ & $23(3.9)$ & $55(4.4)$ \\
\hline Palliative care nursing & $14(2.1)$ & $17(3.0)$ & $31(2.5)$ \\
\hline Neonatal nursing & $13(2.0)$ & $13(2.3)$ & $26(2.1)$ \\
\hline Other & $52(7.7)$ & $66(11.2)$ & $118(9.5)$ \\
\hline \multicolumn{4}{|l|}{ Shift work } \\
\hline Yes & $538(81.1)$ & $412(71.1)$ & $950(76.5)$ \\
\hline No & $125(18.9)$ & $167(28.9)$ & $292(23.5)$ \\
\hline
\end{tabular}

of their professional preparation for the education of other women, and the need to increase their knowledge and skills in this field.

For the proper assessment of performing BSE by nurses, a four-item scale was drawn up of the type single best answer multiple choice question. Each item referred to one principle of the proper performance of BSE $[9,10]$ : regular performance (once a month); examination 2-3 days after the end of menarche in pre-menopausal women and on a chosen day of the month in postmenopausal women; using both visual and palpation technique; examination in standing and lying position. Meeting each principle was awarded with one point to the respondent; total maximum number of points was 4 . The differentiating power of specific items was between $0.12-0.25$.

Statistical Analysis. In the comparative analysis, in the case of nominal variables the Pearson's chi-squared test was applied and in case of unfullfilled Cochran's rule - FisherFreeman-Halton exact test [45]. Student's t-test was used to evaluate the differences for quantitative variables. To assess the effect of size the following were used, depending on the type of used variables: odds ratio (for two nominal variables) and Cohen's $d$ (e standardised difference between two means) with $95 \%$ confidence intervals [46]. Correlation was assessed with the rho-Spearman coefficient. P-values $<0.05$ were considered to be statistically significant. All of the statistical analyses were performed using STATISTICA 13.1 (StatSoft ${ }^{\odot}$, Inc.) under the Medical University of Warsaw licence.

\section{RESULTS}

Performance of breast self-examination by nurses and its accuracy. All surveyed nurses declared to have performed BSE in their life, including $41.1 \%$ who stated that they had performed it at the age of 20 or earlier. Regular breast examination was performed only by $56.7 \%$ of the nurses (Tab. $2)$. In menstruating women $(\mathrm{N}=1,058)$ in the recommended time (2-3 days after the cessation of menstruation), the practice was among $67.3 \%$ nurses, others in different stages of the menstrual cycle). In women after menopause $(\mathrm{N}=184)$ on a chosen day, specific day, the examination was performed only by $30.4 \%$. Nearly all respondents (ca. $98 \%$ of participants performing BSE) applied both visual and palpation techniques, but only $58.9 \%$ did so in two positions: standing up and lying. Age related differences in the analysed indicators of proper performance of the selfexamination were statistically important only in the case of the first examination, as by the age of 20 the procedure was performed by twice as many women by the age 44 than at 45 or more $(\mathrm{OR}=2.82,95 \% \mathrm{CI}$ [2.23-3.57], $\mathrm{P}<0.001)$ (Table 2).

The average number of points in the BSE accuracy scale, taking all four into consideration, was 2.8. All (4 points) or almost all (3 points) recommendations concerning the proper BSE were obtained by $61.4 \%$ of the nurses, and almost every tenth nurse followed no or only one of these recommendations (Tab. 2).

Table 2. Performance and technique of breast self-examination (BSE) by nurses and assessment of self-examination (\%)

\begin{tabular}{|c|c|c|c|c|}
\hline & \multirow{2}{*}{$\begin{array}{c}\text { Total } \\
(\mathrm{N}=1242)\end{array}$} & \multicolumn{2}{|c|}{ Age } & \multirow[b]{2}{*}{ P-value } \\
\hline & & $\begin{array}{c}<44 \text { years } \\
(N=663)\end{array}$ & $\begin{array}{c}\geq 45 \text { years } \\
(N=579)\end{array}$ & \\
\hline \multicolumn{5}{|l|}{$\begin{array}{l}\text { Age when first BSE was } \\
\text { performed }\end{array}$} \\
\hline At 20 or earlier & 41.1 & 52.5 & 28.2 & \multirow{3}{*}{$<0.001^{* *}$} \\
\hline $21-29$ years & 30.0 & 32.6 & 26.9 & \\
\hline 30 years and over & 28.9 & 14.9 & 44.9 & \\
\hline \multicolumn{5}{|l|}{ Frequency of BSE } \\
\hline Once a month & 56.7 & 56.4 & 57.0 & \multirow{5}{*}{$N S^{* *}$} \\
\hline Once every quarter & 25.7 & 25.8 & 25.6 & \\
\hline Once every six months & 11.5 & 11.8 & 11.2 & \\
\hline Once a year & 3.5 & 3.0 & 4.2 & \\
\hline Less often than once a year & 2.6 & 3.0 & 2.0 & \\
\hline \multicolumn{5}{|l|}{ Type of examination } \\
\hline Visual and palpation & 97.8 & 98.2 & 97.2 & \multirow{3}{*}{$\mathrm{NS}^{*}$} \\
\hline Only palpation & 1.5 & 1.1 & 2.1 & \\
\hline Only visual & 0.7 & 0.7 & 0.7 & \\
\hline \multicolumn{5}{|l|}{ Position durung examination } \\
\hline Standing and lying position & 58.9 & 58.2 & 59.6 & \multirow{3}{*}{ NS* } \\
\hline Only standing position & 40.3 & 40.9 & 39.7 & \\
\hline Only lying position & 0.8 & 0.9 & 0.7 & \\
\hline \multicolumn{5}{|l|}{ Accuracy of examination scale } \\
\hline 4 points (completely accurate) & 27.5 & 28.8 & 25.9 & \multirow{6}{*}{$\begin{array}{l}\text { NS }^{* *} \\
\text { NS }^{* * *}\end{array}$} \\
\hline 3 points & 33.9 & 33.9 & 33.9 & \\
\hline 2 points & 25.8 & 25.6 & 26.1 & \\
\hline 1 points & 11.9 & 11.2 & 12.8 & \\
\hline 0 points (inaccurate) & 0.9 & 0.5 & 1.4 & \\
\hline Total score $(\mathrm{M} \pm \mathrm{SD})$ & $2.8 \pm 1.01$ & $2.8 \pm 1.00$ & $2.7 \pm 1.03$ & \\
\hline
\end{tabular}

* Fisher-Freeman-Halton exact test

** Pearson's chi-squared test *** Student's t-test

NS - non-statistical significance

$M-$ mean

SD - standard deviation

Information sources and skills of nurses in breast selfexamination. Almost all nurses (91.1\%) declared having 
received information on the need and rules of breast self-examination. Over half of the respondents stated their gynaecologist (58.8\%) and lecturer in their nursing education course $(51.5 \%)$ as the source of information. A small percentage of respondents obtained such information from nurses and midwives, and a very few from their general practitioner (7.2\%). The percentage of analysed information sources in both age groups was similar, except for mothers who statistically significantly more frequently provided information to younger than older nurses (19.6\% vs. $14.5 \%$, $\mathrm{OR}=1.44$, 95\%CI [1.05-1.98]; $\mathrm{P}=0.030)$. A fairly frequent source of information was the media, most often books/ specialist periodicals and leaflets. Younger nurses more often mentioned the Internet $(40.3 \%$ vs. $31.2 \%, \mathrm{OR}=1.72,95 \% \mathrm{CI}$ [1.31-2.24]; $\mathrm{P}<0.001)$, and less often women's magazines (25.0\% vs. $32.5 \%, \mathrm{OR}=0.70,95 \% \mathrm{CI}[0.53-0.92] ; \mathrm{P}=0.012)$ (Tab. 3).

Only $77.8 \%$ of the nurses stated that they had received instruction (demonstration) on how BSE should be performed. The instructors, as in the case of knowledge, were most often lecturers in the professional education programme (53.3\%) and gynaecologists (44.3\%). Equally rare, as in the case of knowledge, the instructors were nurses (more often in younger persons, $\mathrm{OR}=1.43,95 \% \mathrm{CI}$ [0.99-2.05]; $\mathrm{P}=0.024$ ), midwives (more often in older persons, $\mathrm{OR}=0.64,95 \% \mathrm{CI}$ [0.44-0.95]; $\mathrm{P}=0.050$ ) and mothers (statistically insignificant differences) (Tab. 3).

Table 3. Sources of knowledge and practical skills in breast selfexamination in nurses (\%)

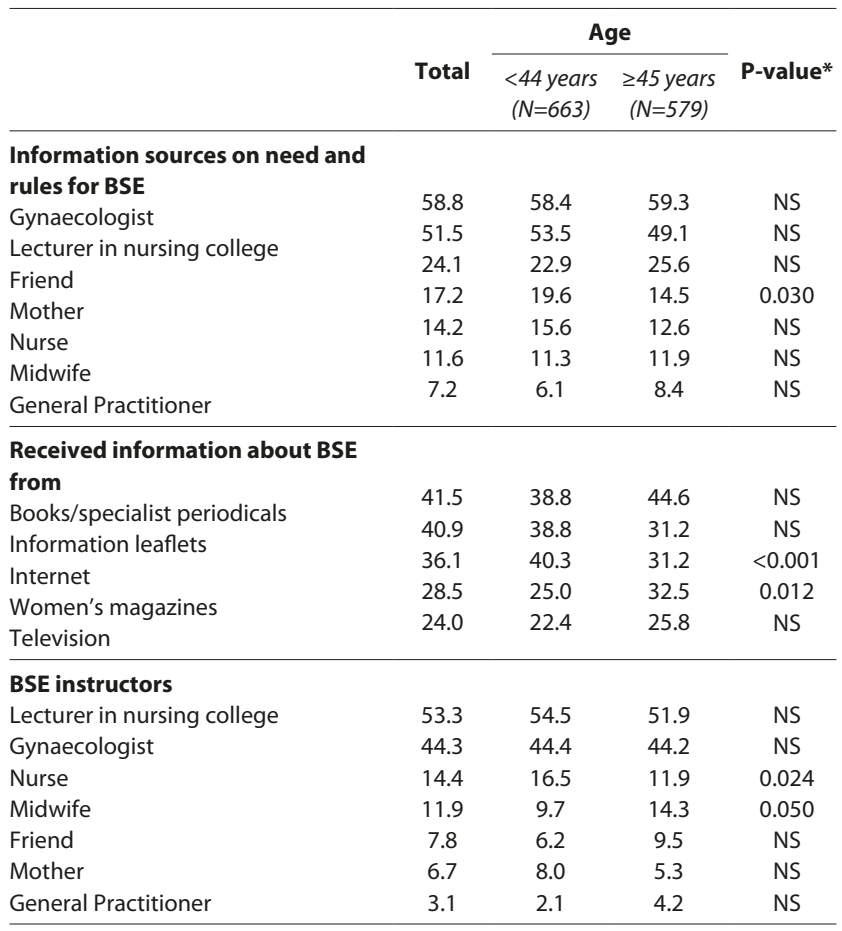

* Pearson's chi-squared test

NS - non-statistical significance

Self-assessment of knowledge, skills of breast selfexamination and preparation of nurses to educate women in this regard. Nearly all the nurses (93.5\%) stated that their knowledge of BSE was good or very good, fewer respondents $(88.8 \%)$ assessed so high their practical skills. The average self-assessment from the aspect of knowledge $(d=-0.18$,
95\%CI [-0.30-0.00]; P $=0.003)$ and skills $(d=-0.23,95 \% \mathrm{CI}$ [-0.35-(-0.12)], $\mathrm{P}<0.001)$ was lower in younger nurses in comparison with older ones (Table 4 ).

Less than half (42.9\%) of the surveyed nurses declared to have educated women in BSE in their professional work. The majority of respondents (69.3\%) considered themselves prepared for this work, but only $7.7 \%$ answered 'definitely yes'. The average self-assessment in the nurses' preparation for such education was lower in the case of younger nurses, compared with older ones $(d=-0.26,95 \%$ CI [-0.37- $(-0.14)]$; $\mathrm{P}<0.001)$. The need to increase knowledge and skills in BSE was reported by $42.7 \%$ nurses (Tab. 4 ).

Table 4. Self-assessment of knowledge, skills of breast self-examination, nurses' preparation to educate women in this regard (\%)

\begin{tabular}{lcccc}
\hline & \multirow{2}{*}{$\begin{array}{c}\text { Total } \\
(N=1242)\end{array}$} & $\begin{array}{c}<44 \text { years } \\
(N=663)\end{array}$ & $\begin{array}{c}\geq 45 \text { years } \\
(N=579)\end{array}$ & P-value \\
\cline { 3 - 4 } & & & & \\
Self-assessment of & & & & \\
BSE knowledge & 27.5 & 24.9 & 30.6 & \\
Very good & 66.0 & 67.1 & 64.8 & $0.013^{*}$ \\
Good & 6.4 & 7.8 & 4.7 & $0.003^{* * *}$ \\
Satisfactory & 0.1 & 0.2 & 0.0 & \\
Unsatisfactory & $4.2 \pm 0.55$ & $4.2 \pm 0.55$ & $4.3 \pm 0.53$ & \\
M \pm SD & & & &
\end{tabular}

\section{Self-assessment of}

BSE practical skills

Very good

Good

Satisfactory

Unsatisfactory

$\mathrm{M} \pm \mathrm{SD}$

$\begin{array}{cccl}19.0 & 16.1 & 22.3 & \\ 69.8 & 69.7 & 69.9 & <0.001^{*} \\ 10.6 & 13.6 & 7.3 & <0.001^{* * *} \\ 0.6 & 0.6 & 0.5 & \\ \mathbf{4 . 0 1 \pm 0 . 5 6} & \mathbf{4 . 0 \pm 0 . 5 7} & \mathbf{4 . 1} \pm \mathbf{0 . 5 4} & \end{array}$

Self-assessment

of preparation to

educate women

about

Definitely yes

Rather yes

Rather not

Definitely no

M \pm SD

7.7

61.6

28.1

26

$3.7 \pm 0.63$

$\begin{array}{ll}4.9 & 10.9\end{array}$

$60.3 \quad 63.1<0.001^{* *}$

$32.0 \quad 23.7<0.001 * * *$

* Fisher-Freeman-Halton exact test; ** Pearson's chi-squared test; *** Student's t-test

M - mean; SD - standard deviation

Relationship between self-assessment of knowledge and skills in breast self-examination and its accuracy. The self-assessment of nurses in BSE was significantly correlated with the result in the accuracy scale of the examination. The relationship concerned both the self-assessment from the aspect of knowledge and skills (rho 0.165 and 0.191 , respectively). Moreover, a similar relationship was observed, but with lower intensity in the group performing BSE frequently, i.e. once a month (rho 0.118 and 0.109, respectively).

\section{DISCUSSION}

The presented results of the cross-sectional study, carried out in a large group $(\mathrm{N}=1,242)$ of Polish nurses concern the performance of BSE, its accuracy and self-assessment of knowledge and skills in this aspect. The undertaking of this study was justified by the unfavourable epidemiological situation regarding breast cancer in Poland (increasing incidence rate, low 5-year survival for patients diagnosed with breast cancer, low participation rate in the screening 
programme in population aged $50-69$ years), an increased risk of this cancer in nurses (shift work, unhealthy lifestyle), and the need for their participation in patient education in the prevention of breast cancer.

In the group of Polish nurses who were specialists in different nursing areas, many inconsistencies were found in the frequency, times, and technique of BSE. Only $56.7 \%$ of the nurses performed BSE regularly, i.e. monthly. The percentage was lower in Poland, in the United Arab Emirates (61.5\%) [39] and much higher than in India (15.6\%) [38]. Among the surveyed female health care workers, nurses among them, in Turkey 17\% [34], Iran 6\% [35] and 39.5\% regularly practised BSE [36]. In Poland, on the recommended or chosen date, BSE was performed by $67.3 \%$ nurses with regular menstruation, and by only $30.4 \%$ post-menopausal respondents. Almost all surveyed nurses used visual and tactile examination, while only $58.9 \%$ performed the examination both in the standing and lying position.

Most often, the information and rules of BSE, as well as the instructions, were provided by gynaecologists and lecturers as part of the education in preparing for the nursing profession. However, it seems an alarming fact that only half of the respondents received information and instruction from their lecturers during their education. This indicates insufficient education about BSE in Polish nursing colleges. A similar situation was described in Saudi Arabia [40], Turkey [41] and Iraq [47]. Positive correlations between nursing students BSE practice and their academic experience in nursing college were found in Saudi Arabia [40]. Among the surveyed nurses in Poland, nurses, midwives and mothers were rarely a source of practical skills. Information from different media, including books and professional periodicals, was obtained by $24-41 \%$ respondents.

Considering the four items recommended as proper BSE it was found that only $61.4 \%$ of nurses met all or almost all recommendations (obtained $3-4$ points in the accuracy scale). Simultaneously, $93.5 \%$ of surveyed nurses assessed their knowledge about BSE, and $88.8 \%$ their practical skills as good or very good. This suggests that differences exist between nurses' statements regarding their knowledge and skills, and their application in BSE. The level of selfassessment of knowledge and BSE skills were significantly correlated with the proper performance of this examination.

Analysis of the results with consideration of age, demonstrates that younger nurses ( $<44$ years), when compared with older ones ( $\geq 45$ years), statistically significantly earlier started BSE at the age of 20 or before, received information about BSE from mothers, the Internet and women's magazines, or were instructed by nurses and midwives. This may result from their greater awareness as young adults and through their mothers, better skills at using information technology, as well as the availability of women's magazines with information on various aspects of health. Older nurses assessed their knowledge and skills, together with the preparation to educate women in BSE, as better than the younger ones No significant age related differences were found in the accuracy of performing BSE.

Only $42.9 \%$ of nurses educated women in BSE in their present professional practice, nearly three times more than they had been educated in the past by nurses (only $14 \%$ of respondents nurses were sources of information on the need and rules of BSE, and played the role of instructors). It may be assumed that the nurses' participation in women's education in breast cancer prevention has increased in Poland. Further research is needed to confirm this hypothesis. Most nurses $(69.3 \%)$ considered themselves to be prepared to educate women and $42.7 \%$ wish to increase their competences in BSE.

A limitation of the this study is its performance in a nonrepresentative group. The surveyed nurses undertook action to improve their qualifications and it may be concluded that the obtained results are more positive than in an average nurse group in Poland. The questionnaire enquired only about BSE, no other methods of screening were taken into account. It may be assumed that some nurses attended mammography and believed it was not obligatory to practice BSE. This issue also requires further research.

\section{CONCLUSIONS}

The presented results of this survey indicate that Polish nurses highly value their knowledge and skill in BSE skills which ise one of the commonly available and recommended techniques for breast cancer prevention. However, a significant percentage of nurses still fail to perform BSE, or to follow the agreed rules. Only half of the nurses received BSE information and instruction from their lecturers in the course of education in preparation for the nursing profession. This shows the need to include these issues in the nurses' pre-diploma and post-diploma education, and also within the framework of workplace training. This is essential from the point of view of breast cancer prevention among nurses themselves and their bigger involvement in the education of women, patients, and increasing the effectiveness of this education.

\section{REFERENCES}

1. Wojciechowska U, Olasek P, Czauderna K, Didkowska J. Cancer in Poland in 2016. Warsaw: Centrum Onkologii im. M. SkłodowskiejCurie; 2014

2. National Cancer Registry. Breast cancer among women (C50), http:// onkologia.org.pl/nowotwory-piersi-kobiet; [accessed 10 may 2017]

3. Altobelli E, Lattanzi A. Breast cancer in European Union: an update of screening programmes as of March 2014 (review). Int J Oncol. 2014;45:1785-92.

4. Allemani C, Weir HK, Carreira H, Harewood R, Spika D, Wang XS, et al. Global surveillance of cancer survival 1995-2009: analysis of individual data for $25,676,887$ patients from 279 population-based registries in 67 countries (CONCORD-2). Lancet 2015; 385: 977-1010.

5. Bielska-Lasota M, Krzyżak M, Kwiatkowska K, Bogusz J, Maślach D, Wysocki MJ. Differences in treatment outcomes in selected cancers in Poland compared to other European countries in 2005-2009, based on CONCORD 2 study. Nowotwory 2016; 66: 202-11.

6. International Agency for Research on Cancer World Health Organization. Breast cancer screening. IARC handbooks of cancer prevention. Lyon: IARC Press 7; 2002.

7. National Programme for the Prevention of Cancer. Multiannual program for 2016-2024 http://www.mz.gov.pl/zdrowie-i-profilaktyka/ programy-zdrowotne/wykaz-programow/narodowy-programzwalczania-chorob-nowotworowych/narodowy-program-zwalczaniachorob-nowotworowych-na-lata-2016-2024; 2015 [accessed 10 May 10 2017].

8. European Commission. Against cancer. Cancer screening in the European Union. Report on the implementation of Council Recommendation on cancer screening. 2017.

9. Khatib O, Modjtabal A. Guidelines for the early detection and screening of breast cancer. EMIRO Technical Publication Series 30. Cairo: World Health Organization Regional Office for the Eastern Mediterranean; 2006. 
10. Knutson D, Steiner E. Screening for breast cancer: current recommendations and future directions. Am Fam Physician 2007; 75: $1660-6$.

11. Austoker J. Screening and self examination for breast cancer. BMJ 1994; 309: 168-74.

12. Baxter N. Preventive health care, 2001 update: should women be routinely taught breast self-examination to screen for breast cancer? CMAJ 2001; 164: 1837-46.

13. Zografos GC, Sergentanis TN, Zagouri F, Papadimitriou CA, Domeyer $\mathrm{P}$, Kontogianni PN, et al. Breast self-examination and adherence to mammographic follow-up: an intriguing diptych after benign breast biopsy. Eur J Cancer Prev. 2010; 19: 71-2.

14. Coleman C. Early detection and screening for breast cancer. Semin Oncol Nurs. 2017; 33: 141-55.

15. Anastasi N, Lusher J. The impact of breast cancer awareness interventions on breast screeening uptake among woman in the United Kingdom: A systematic review. J Health Psychol. 2019; 24: 113-24.

16. DeSantis C, Siegel R, Jemal A. Breast Cancer Facts \& Figures 2015-2016. Atlanta: American Cancer Society; 2016.

17. Schernhammer ES, Kroenke CH, Laden F, Hankinson SE. Night work and risk of breast cancer. Epidemiology 2006; 17: 108-11.

18. Schernhammer ES, Laden F, Speizer FE, Willett WC, Hunter DJ, Kawachi I, et al. Rotating night shifts and risk of breast cancer in women participating in the nurses' health study. J Natl Cancer Inst. 2001; 93: 1563-8.

19. Lie JA, Roessink J, Kjaerheim K. Breast cancer and night work among Norwegian nurses. Cancer Causes Control. 2006; 17: 39-44.

20. Lie JA, Kjuus H, Zienolddiny S, Haugen A, Stevens RG, Kjaerheim K. Night work and breast cancer risk among Norwegian nurses: assessment by different exposure metrics. Am J Epidemiol. 2011; 173: 1272-9.

21. Stevens RG. Electric power use and breast cancer: a hypothesis. Am J Epidemiol. 1987; 125: 556-61.

22. Blask DE, Hill SM, Dauchy RT, Xiang S, Yuan L, Duplessis T, et al. Circadian regulation of molecular, dietary, and metabolic signaling mechanisms of human breast cancer growth by the nocturnal melatonin signal and the consequences of its disruption by light at night. J Pineal Res. 2011; 51: 259-69.

23. Peplonska B, Bukowska A, Lie JA, Gromadzinska J, Zienolddiny S. Night shift work and other determinants of estradiol, testosterone and dehydroepiandrosterone sulfate among middle-aged nurses and midwives. Scand J Work Environ Health 2016; 42: 435-46.

24. Straif K, Baan R, Grosse Y, Secretan B, El Ghissassi F, Bouvard V, et al. Carcinogenicity of shift-work, painting, and fire-fighting. Lancet Oncol. 2007; 8: 1065-6.

25. Kolstad HA, Erlandsen M, Frost P, Bonde JP. Should we warn against night shifts to prevent breast cancer? Occup Environ Med. 2010; 67: 797.

26. Kolstad HA. Nightshift work and risk of breast cancer and other cancers--a critical review of the epidemiologic evidence. Scand J Work Environ Health 2008; 34: 5-22.

27. Kamdar BB, Tergas AI, Mateen FJ, Bhayani NH, Oh J. Night-shift work and risk of breast cancer: a systematic review and meta-analysis. Breast Cancer Res Treat 2013; 138: 291-301.

28. Megdal SP, Kroenke CH, Laden F, Pukkala E, Schernhammer ES. Night work and breast cancer risk: a systematic review and meta-analysis. Eur J Cancer. 2005; 41: 2023-32.

29. Travis RC, Balkwill A, Fensom GK, Appleby PN, Reeves GK, Wang XS, et al. Night Shift Work and Breast Cancer Incidence: Three Prospective
Studies and Meta-analysis of Published Studies. J Natl Cancer Inst. 2016; 108: djw169.

30. Persson M, Mårtensson J. Situations influencing habits in diet and exercise among nurses working night shift. J Nurs Manag. 2006; 14: 414-23.

31. Tucker SJ, Harris MR, Pipe TB, Stevens SR. Nurses' ratings of their health and professional work environments. AAOHN J. 2010; 58: 253-67.

32. Zapka JM, Lemon SC, Magner RP, Hale J. Lifestyle behaviours and weight among hospital-based nurses. J Nurs Manag. 2009; 17: 853-60.

33. Panczyk M, Woynarowska-Sołdan M, Żmuda-Trzebiatowska H, Gotlib J. Health enhancing behaviours of nurses in Poland and their association with shift work and age. Collegian 2018; 25: 255-61.

34. Güleser GN, Ünalan D, Akyldz HY. The knowledge and practice of breast self-examination among healthcare workers in Kayseri, Turkey. Cancer Nurs. 2009; 32: E1-E7.

35. Haji-Mahmoodi M, Montazeri A, Jarvandi S, Ebrahimi M, Haghighat S, Harirchi I. Breast Self-Examination: Knowledge, Attitudes, and Practices Among Female Health Care Workers in Tehran, Iran. Breast J. 2002; 8: 222-5.

36. Reisi M, Javadzade SH, Sharifirad G. Knowledge, attitudes, and practice of breast self-examination among female health workers in Isfahan, Iran. J Educ Health Promot. 2013; 2: 46.

37. Ahmed F, Mahmud S, Hatcher J, Khan SM. Breast cancer risk factor knowledge among nurses in teaching hospitals of Karachi, Pakistan: a cross-sectional study. BMC Nurs. 2006; 5: 6.

38. Srivastava K, Jethani S, Kalthe B, Khilnani PS, Bhawalkar JS, Vyas S. Awareness of Breast Cancer Risk Factors and Practice of Breast Self-Examination among Nurses of Tertiary Care Hospital. Ind J For Comm Med. 2016; 3: 75-78.

39. Sreedharan J, Muttappallymyalil J, Venkatramana M, Thomas M. Breast self-examination: knowledge and practice among nurses in United Arab Emirates. Asian Pacific J Canc Prev. APJCP 2010; 11: 651-4.

40. Alsaif AA. Breast self-examination among Saudi female nursing students in Saudi Arabia. Saudi Med J. 2004; 25: 1574-8.

41. Ardahan M, Dinc H, Yaman A, Aykir E, Aslan B. Health Beliefs of Nursing Faculty Students about Breast Cancer and Self Breast Examination. Asian Pac J Cancer Prev. 2015; 16: 7731-6.

42. Karadag M, Iseri O, Etikan I. Determining Nursing Student Knowledge, Behavior and Beliefs for Breast Cancer and Breast Self-examination Receiving Courses with Two Different Approaches. Asian Pac J Cancer Prev. 2014; 15: 3885-90.

43. Yucel SC, Orgun F, Tokem Y, Avdal EU, Demir M. Determining the Factors that Affect Breast Cancer and Self Breast Examination Beliefs of Turkish Nurses in Academia. Asian Pac J Cancer Prev. 2014; 15: 1275-80.

44. Sapountzi-Krepia D, Rekleiti M, Lavdanti M, Psychogiou M, Chaliou M, Xenofontos M, Savva M. Evaluating female nursing students' knowledge and attitudes regarding breast self-examination. Health Care Woman Int. 2017; 38: 786-95.

45. Sharpe D. Your chi-square test is statistically significant: Now what? Practical Assessment, Research \& Evaluation 2015; 20: 1-10.

46. Ferguson CJ. An effect size primer: A guide for clinicians and researchers. Professional Psychology: Research and Practice 2009; 40: $532-538$.

47. Ebrahim SM. Knowledge of students toward breast cancer and breast self-examination practice at high school nursing in Basra city. Kufa Journal for Nursing Sciences 2014; 4: 84-92.

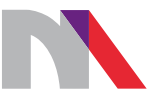

Ministry of Science and Higher Education

Republic of Poland

Generation of the DOI (Digital Object Identifier) - task financed under the agreement No. 618/P-DUN/2019 by the Minister of Science and Higher Education 